\title{
Severe Imported Malaria in a Serbian Referral Center
}

Jasmina S Poluga $a^{1,2}$, Uroš R Karić ${ }^{*}$, Olga S Dulović ${ }^{1,2}$, Zorica D Dakić ${ }^{3}$, Nataša A Popović ${ }^{1}$, Branko B Milošević ${ }^{1,2}$, Aleksandar M Urošević ${ }^{1,2}$, Lidija S Lavadinović $^{1}$ and Milorad D Pavlović ${ }^{1,2}$

${ }^{1}$ Infectious and Tropical Diseases University Hospital, Clinical Centre of Serbia, Bulevar oslobođenja, Belgrade, Serbia

${ }^{2}$ Belgrade University School of Medicine, Doktora Subotića, Belgrade, Serbia

${ }^{3}$ Parasitological Laboratory, Department of Microbiology, Clinical Center of Serbia, Bulevar oslobođenja, Belgrade, Serbia

*Corresponding author: Karić UR, Infectious and Tropical Diseases University Hospital, Clinical Centre of Serbia, Kralja Petra Prvog, $3 / 12,14224$ Lajkovac, Serbia, Tel: +38163363042; Fax: +38163363042; E-mail: uroskaric@gmail.com

Received date: February 06, 2017; Accepted date: February 16, 2017; Published date: February 26, 2017

Copyright: (C) 2017 Poluga JS, et al. This is an open-access article distributed under the terms of the Creative Commons Attribution License, which permits unrestricted use, distribution, and reproduction in any medium, provided the original author and source are credited.

\section{Abstract}

Background: World Health Organization estimates that 3.2 billion people are at risk of being infected with malaria. Thus, adequate diagnostic protocols for malaria, especially those aimed at determining disease severity, are paramount in both endemic and non-endemic settings.

Methods: We analyzed 22 patients with severe malaria and compared their clinical and laboratory findings with those of patients with non-severe malaria in search of predictors of disease severity. All patients were treated at the Infectious and Tropical Diseases University Hospital, Clinical Centre of Serbia in Belgrade, Serbia from 2000 to 2010.

Results: Average age was $44.86 \pm 12.33$ years and men predominated $(95.45 \%)$ among patients with severe malaria. Patients with severe malaria were infected with $P$. falciparum significantly more frequently compared with those with non-severe disease $(p=0.047)$. Jaundice was the most commonly observed feature of severe malaria, followed by anemia and renal failure. A multifactor analysis of variance showed that thrombocytopenia $(p=0.05)$ and high serum TNF-alpha levels $(p=0.02)$ were significantly associated with disease severity.

Conclusion: A high index of suspicion for malaria should be maintained when evaluating febrile patients returning from malaria endemic regions. Elevated serum TNF-alpha levels and thrombocytopenia are associated with severe malaria in non-endemic settings.

Keywords: Malaria; Serbia; Thrombocytopenia; Tumor necrosis factor-alpha

\section{Introduction}

World Health Organization (WHO) estimates that some 3.2 billion people (about $44 \%$ of the world's population) are at risk of being infected with malaria and developing the disease [1]. Some 214 million cases of malaria were reported in 2015 and resulted in 438000 deaths [2]. The WHO African region carries a disproportionately high share of the global malaria burden, considering it was home to $88 \%$ of malaria cases and $90 \%$ of malaria deaths in 2015 [2].

Severe malaria is defined by clinical or laboratory evidence of vital organ dysfunction [3]. In 1990, WHO established the criteria for severe malaria in order to facilitate future clinical and epidemiological studies [4]. In the year 2000, these criteria were revised to include other clinical and laboratory abnormalities that portend a poor prognosis based on clinical experience in semi-immune patients [5]. Plasmodium falciparum is the most common cause of severe malaria, but Plasmodium vivax and Plasmodium knowlesi can also cause severe disease [6]. Although rare, Plasmodium ovale has also been reported in patients with severe malaria [7].

The circulating level of TNF-alpha was shown to be a marker of organ failure and, as such, was correlated to malaria severity [8-10].
Low thrombocyte counts were also proven to be related to the severity of both vivax and falciparum malaria, although some authors questioned their usefulness for triage and prognostication [11-13]. Most studies correlating platelet counts and TNF-alpha levels to disease severity were conducted in endemic settings [9-13].

In 1975, WHO announced that malaria was eradicated from Europe, with what was then the Socialist Federal Republic of Yugoslavia designated as malaria free since 1964. This meant that malaria was also eradicated from Serbia which was one of the six republics constituting the federation [14]. However, imported malaria remained a concern in the years to follow [15].

The aim of this study was to identify the demographic, parasitological, clinical and laboratory characteristics associated with severe malaria in a non-endemic setting.

\section{Materials and Methods}

We conducted a case control study in order to analyze the clinical, laboratory and parasitological characteristics of severe malaria in the Republic of Serbia.

Researchers browsed through archived paper-based medical records and identified all patients that were treated for malaria at Infectious and Tropical Diseases University Hospital, Clinical Centre of Serbia in Belgrade, Serbia in an 11 year period (2000-2010). 
Page 2 of 5

Infectious and Tropical Diseases University Hospital is a tertiary health care facility that treats patients with infectious and/or tropical diseases that cannot be diagnosed and/or treated in other hospitals in Serbia and patients who reside in the capital city of Belgrade and present directly to the clinic.

Researchers then analyzed the selected medical records and determined which subset of malaria patients met the criteria for severe disease.

Severe malaria was defined according to WHO criteria as the presence of one of the following in a patient with a parasitological diagnosis of malaria: hyperparasitemia (more than 5\% parasitized erythrocytes), shock, abnormal bleeding, pulmonary edema/ARDS, jaundice (a bilirubin concentration higher than $50 \mu \mathrm{mol} / \mathrm{L}$ ), renal failure (a urine output $<400 \mathrm{ml}$ per 24 hours and a serum creatinine concentration higher than $265 \mu \mathrm{mol} / \mathrm{L}$ ), severe anemia (a hemoglobin concentration less than $7 \mathrm{~g} / \mathrm{dL}$ or a hematocrit less than 20\%), hemoglobinuria, impaired consciousness (a Glasgow coma score less than 11), prostration, multiple convulsions (at least two convulsions in 24 hours), acidosis (a bicarbonate concentration less than $15 \mathrm{mmol} / \mathrm{l}$ or arterial/capillary $\mathrm{pH}$ lower than 7.25 ), hyperlactatemia (an arterial lactate concentration $>5 \mathrm{mmol} / \mathrm{L}$ ) hypoglycemia (a plasma glucose concentration lower than $2.2 \mathrm{mmol} / \mathrm{L}$ ) [5]. Patients with non-severe malaria were used as controls.

Findings on physical examination, parasitological and immunological investigation and blood chemistry panel and complete blood count results were entered into a Microsoft Excel 2010 document.

We determined the TNF-alpha concentration in the patients' serum using an ELISA-based standardized kit called the Quantikine ELISA Kit (R\&D Systems) and examined thick and thin peripheral blood stained with Giemsa. Parasitemia was expressed as a percentage of parasitized erythrocytes.

Statistical analysis was preformed using IMB's SPSS Statistics v14 utilizing the methods of descriptive statistics, the chi-squared test, Fisher's exact test (where assumptions for chi-squared test were not met) and multivariate analysis of variance (MANOVA).

We analyzed average patient age, malaria chemoprophylaxis compliance, immunity to malaria, the presence of comorbidities, symptoms duration before admission to hospital, severe thrombocytopenia (platelet count $<50,000$ ) and the TNF- $\alpha$ level as possible predictors of severe malaria using MANOVA.

The authors obtained ethical approval from the Ethical committee of School of Medicine, University of Belgrade.

\section{Results}

We identified 103 patients treated for malaria at Infectious and Tropical Diseases University Hospital, Clinical Centre of Serbia from 2000 to 2010.

\begin{tabular}{|l|l|l|l|l|}
\hline \multirow{2}{*}{ Age (years) } & \multicolumn{2}{|l|}{ Number of patients } & \multicolumn{2}{l|}{ Percentage of patients (\%) } \\
\cline { 2 - 5 } & Non-severe & Severe & Non-severe & Severe \\
\hline $0-10$ & 1 & 0 & 1.23 & 0 \\
\hline $11-20$ & 1 & 0 & 1.23 & 0 \\
\hline $21-30$ & 6 & 3 & 7.41 & 13.64 \\
\hline $31-40$ & 14 & 4 & 17.28 & 18.18 \\
\hline $41-50$ & 22 & 6 & 27.16 & 27.27 \\
\hline $51-60$ & 24 & 8 & 29.63 & 36.36 \\
\hline $61-70$ & 13 & 1 & 16.05 & 4.55 \\
\hline Total & 81 & 22 & 100 & 100 \\
\hline
\end{tabular}

Table 1: Age distribution.

A subgroup of 22 patients (21.35\%) met the criteria for severe malaria at presentation. Men predominated (95.45\%) and average patient age was $44.86 \pm 12.33$ years (range 21-61 years).

The age distribution of patients with severe malaria is represented in Table 1. It was not statistically significantly different than the age distribution of patients with non-severe malaria (Fisher's exact test, $\mathrm{p}=0.759$ ).

A single patient fulfilled five criteria for severe malaria and suffered a lethal outcome (Table 3). No patient met more than five criteria. We did not analyze the correlation between the number of fulfilled criteria and disease outcome due to the sparsity of data.

\begin{tabular}{|c|c|c|c|c|}
\hline \multirow{2}{*}{ Plasmodium species } & \multicolumn{2}{|c|}{ Number of patients } & \multicolumn{2}{|c|}{ Percentage of patients (\%) } \\
\hline & Severe & Non-severe & Severe & Non-severe \\
\hline Plasmodium falciparum & 19 & 56 & 86.38 & 69.13 \\
\hline Plasmodium falciparum + vivax & 1 & 4 & 4.54 & 4.94 \\
\hline Plasmodium vivax & 1 & 19 & 4.54 & 23.46 \\
\hline Plasmodium ovale & 1 & 0 & 4.54 & 0 \\
\hline Plasmodium malariae & 0 & 2 & 0 & 2.47 \\
\hline Total & 22 & 81 & 100 & 100 \\
\hline
\end{tabular}

Table 2: Patient distribution by Plasmodium species.

The three patients that suffered a fatal outcome all had severe malaria making the overall lethality of malaria $2.91 \%$ and the lethality of severe malaria $13.64 \%$. The majority of patients with severe malaria were infected with $P$. falciparum (90.9\%) which is a statistically 
Citation: Poluga JS, Karic UR, Dulovic OS, Dakic ZD, Popovic NA, et al. (2017) Severe Imported Malaria in a Serbian Referral Center. J Trop

Page 3 of 5

significant difference compared with patients with non-severe forms of the disease (Fisher's exact test, $\mathrm{p}=0.047$ ).

\begin{tabular}{|c|c|c|}
\hline $\begin{array}{l}\text { Number of fulfilled } \\
\text { criteria }\end{array}$ & $\begin{array}{l}\text { Number } \\
\text { patients }\end{array}$ & Percentage of patients (\%) \\
\hline 1 & 13 & 59.10 \\
\hline 2 & 4 & 18.19 \\
\hline 3 & 3 & 13.63 \\
\hline 4 & 1 & 4.54 \\
\hline 5 & 1 & 4.54 \\
\hline Total & 22 & 100 \\
\hline
\end{tabular}

Table 3: Distribution of patients with severe malaria according to the number of fulfilled WHO criteria.
We identified $P$. vivax in the blood of 2 patients with severe malaria, whereas one patient had malaria caused by $P$. ovale. No patients with severe malaria were infected with $P$. malariae.

A vast majority of patients with severe malaria (95.45\%) had a single Plasmodium species as the causative agent. One patient had a mixed $P$. falciparum and $P$. vivax infection (Table 2).

Thirteen patients $(59.10 \%)$ fulfilled only one criteria for severe malaria at presentation, while $9(40.90 \%)$ had two or more criteria.

Patient distribution according to the features of severe malaria is represented in Table 4.

Jaundice was present in $28.21 \%$ of patients making it the most commonly fulfilled criterion for severe malaria in our cohort $\left(\chi^{2}=22.744, \mathrm{p}=0.05\right)$.

\begin{tabular}{|l|l|l|}
\hline Features of severe malaria (WHO criteria) & Number of patients & Percentage of patients (\%) \\
\hline Cerebral malaria & 3 & 7.69 \\
\hline Pulmonary edema/ARDS & 2 & 5.12 \\
\hline Renal failure & 4 & 10.26 \\
\hline Disseminated intravascular coagulation & 1 & 2.56 \\
\hline Jaundice & 11 & 28.21 \\
\hline Anemia & 7 & 17.95 \\
\hline Haemoglobinuria & 1 & 2.56 \\
\hline Hyperparasitemia & 10 & 25.65 \\
\hline
\end{tabular}

Table 4: Distribution of patients according to the features of severe malaria.

No criteria of disease severity aside from those represented in Table 4 were fulfilled by patients in the study cohort. Two patients with severe malaria had arterial hypertension, while one had diabetes mellitus. The rest had no comorbidities.

The average TNF-alpha serum level was $31.91 \mathrm{pg} / \mathrm{ml}$. Fourteen patients $(63.63 \%)$ had severe thrombocytopenia (less than $50 \times 10^{9}$
thrombocytes/L). The MANOVA revealed that patients with severe malaria had statistically significantly higher levels of TNF- $\alpha(p=0.02)$ and statistically significantly higher frequency of severe thrombocytopenia $(\mathrm{p}=0.05)$ compared with patients with non-severe malaria (Table 5).

\begin{tabular}{|l|l|l|l|}
\hline Variables & Non-severe malaria & Severe malaria & F \\
\hline Age (years) & 47.47 & 43.68 & 0.48 \\
\hline Lack of Chemoprophylaxis (\% of patients) & 75.31 & 77.28 & 1.69 \\
\hline Absence of Immunity (\% of patients) & 46.92 & 50.00 & 13.63 \\
\hline Comorbidities (\% of patients) & 23.45 & 7.23 & 0.84 \\
\hline Duration of symptoms (days) & 6.47 & 31.91 & 0.15 \\
\hline Serum TNF- $\alpha$ level $(\mathrm{pg} / \mathrm{mL})$ & 17.12 & 63.63 & 0.03 \\
\hline Number of platelets $<50.000$ (\% of patients) & 18.52 & 5.79 \\
\hline
\end{tabular}

Table 5: Multivariate analysis of variance (MANOVA). 


\section{Discussion}

Data is lacking when it comes to the severe forms of malaria in countries where the disease is not endemic because most studies can include only a small number of patients [16]. The results of our study show that $21.35 \%$ of patients had severe malaria according to WHO criteria. Other authors have found that the proportion of patients with severe disease varies from 1 to $38 \%$ of the total number of patients with malaria [17]. Variations in the percentage of patients with the severe form of malaria are best illustrated by the following: the disease was severe in $7.5 \%$ of patients with malaria in Canada, in $15.9 \%$ in the US and $16 \%$ in the UK [18-20]. In Germany, $27.9 \%$ of patients with malaria caused by $P$. falciparum had severe disease [21].

The vast majority of patients in our study (approximately 91\%) had malaria caused by $P$. falciparum, which is in concordance with data from other studies. Both this and other studies have indicated that severe malaria can be caused by $P$. vivax, the so called "falciparum like" syndrome [22-25]. No cases of severe $P$. knowlesi malaria were reported in Serbia in the analyzed time span. In our study, $P$. falciparum was significantly over-represented in the subgroup of patients with severe malaria compared with those with non-severe malaria.

This study shows that the most common features of severe malaria are the following (listed by decreasing frequency): jaundice, hyprparasitemia, anemia, renal failure, cerebral malaria, pulmonary edema/ARDS. Haemoglobinuria (also called blackwater fever) and disseminated intravascular coagulation (DIC) occurred in one patient each. According to research by authors from Germany and Spain, hyperbilirubinemia and hyperparasitemia were most commonly associated severe malaria $[21,26]$. A multicentric study from Thailand showed that jaundice was present in 529 of 1050 patients (50.4\%) with severe malaria and a hyperparasitemia was present in $33.3 \%$ [27].

Cerebral malaria, renal failure, ARDS, anemia and DIC were most commonly associated with a fatal outcome in the US [28]. In this study, fatal outcomes occurred in 3 patients (2.91\%) the immediate causes of death being cerebral malaria, renal failure and pulmonary edema/ ARDS.

Many studies have shown that increasing age is a risk factor for severe malaria although some authors have questioned this view [29-33]. The average age of patients with severe malaria in this study was approximately 44 years and statistical analysis lead us to the conclusion that old age was not a risk factor for severe malaria. The lack of chemoprophylaxis is the second most commonly cited risk factor for severe malaria $[29,34,35]$. Extensive research that had been conducted in France form 1996 to 2003 and included the results from 120 reference laboratories analyzed at the National Center for imported and autochthonous malaria, showed an association between the severe malaria and increasing age, lack of chemoprophylaxis and duration of symptoms before diagnosis [34]. No such associations were proven in this study. The absence of acquired immunity to malaria was not a risk factor for the development of severe disease; a finding similar to those of French authors [36]. Moreover, previous research suggests that congenital immunity is of greater importance, and that acquired immunity depends on the long-term exposure to malaria parasites making it generally limited to areas of high endemicity [37].

According to the results of our study, patients with severe malaria had significantly higher TNF- $\alpha$ levels and a significantly higher frequency of severe thrombocytopenia compared with patients with non-severe disease. A retrospective study that had been conducted at
The University Hospital in Heidelberg, Germany and included 122 patients with falciparum malaria, showed that thrombocytopenia was a significant predictor of severe malaria [21]. These findings were corroborated by other authors [20,38]. In severe malaria, the concentrations of proinflammatory cytokines such as TNF- $\alpha$, IL-1, IL-6, and IL-12 are elevated [39]. The high level of TNF- $\alpha$ in patients with falciparum malaria correlates with disease severity, hypoglycemia, hyperparasitemia, jaundice, renal failure, cardiovascular complications and death [40]. Many studies have shown a statistically significant correlation between severe malaria and TNF- $\alpha$ levels, the presence of hyperparasitemia, jaundice and acute renal failure [41,42].

\section{Conclusion}

Even though it is a rare cause of morbidity in a non-endemic setting, a high index of suspicion for malaria should be maintained when evaluating febrile patients returning from malaria endemic regions. TNF-alpha is significantly higher and thrombocytes are significantly lower in patients with severe malaria in both endemic and non-endemic settings and Serbia is no exception. Other proinflammatory cytokines may also represent a viable early diagnostic test for predicting malaria severity and present us with an avenue of future research. Since $P$. falciparum causes a large proportion of imported malaria cases in Serbia and is most strongly associated with severe disease (lethal in one in eight patients), the identification of Plasmodium spp. in a patient's blood or even a febrile illness in a patient returning from a $P$. falciparum endemic region, should prompt the clinician to request a determination of TNF-alpha levels and platelet counts in order to take measures to prevent and/or more effectively treat possible organ failure. Whether this approach is costeffective remains to be elucidated.

\section{References}

1. (2015) World Health Organization, Malaria.

2. World Health Organization (2015) World Malaria Report. WHO, Geneva.

3. World Health Organization (2013) Management of severe malaria: a practical handbook. WHO Press, Geneva.

4. No authors listed (1990) Severe and complicated malaria. World Health Organization, Division of Control of Tropical Diseases. Trans R Soc Trop Med Hyg 84: 1-65.

5. No authors listed (2000) Severe falciparum malaria. World Health Organization, Communicable Diseases Cluster. Trans R Soc Trop Med Hyg 94: 1-90.

6. World Health Organisation (2015) Guidelines for the treatment of malaria. WHO Press, Geneva.

7. Strydom KA, Ismail F, Frean J (2014) Plasmodium ovale: A case of notso-benign tertian malaria. Malar J 10: 85.

8. Kern P, Hemmer CJ, Van Damme J, Gruss HJ, Dietrich M, et al. (1989) Elevated tumor necrosis factor alpha and interleukin-6 serum levels as markers for complicated Plasmodium falciparum malaria. Am J Med 87: 139-143.

9. Scuderi P, Sterling KE, Lam KS, Finley PR, Ryan KJ, et al. (1986) Raised serum levels of tumour necrosis factor in parasitic infections. Lancet 13: 1364-1365.

10. Day NP, Hien TT, Schollaardt T, Loc PP, Chuong LV, et al. (1999) The prognostic and pathophysiologic role of pro- and antiinflammatory cytokines in severe malaria. J Infect Dis 180: 1288-1297.

11. Hanson J, Phu NH, Hasan MU, Charunwatthana P, Plewes K, et al. (2015) The clinical implications of thrombocytopenia in adults with severe falciparum malaria: a retrospective analysis. BMC Med 24: 97. 
12. Leowattana W, Tangpukdee N, Thar SK, Nakasiri S, Srivilairit S, et al (2010) Changes in platelet count in uncomplicated and severe falciparum malaria. Southeast Asian J Trop Med Public Health 41: 1035-1041.

13. Saravu K, Docherla M, Vasudev A, Shastry BA (2011) Thrombocytopenia in vivax and falciparum malaria: An observational study of 131 patients in Karnataka. India Ann Trop Med Parasitol 105: 593-598.

14. Popovic B, Mikic D, Zeljkovic J, Čekanac R, Vidanović M (2008) Malaria in Serbian army at Salonika front with special reference to the beginning of the epidemic in mid-1916. General medicine 14: 37-44.

15. Dakić Z, Pelemiš M, Lavadinović L, Nikolić A, Stevanović G, et al. (2011) Imported malaria in Belgrade, Serbia, between 2001 and 2009. Wien Klin Wochenschr 123: 15-19.

16. Seringe E, Thellier M, Fontanet A, Legros F, Bouchaud O, et al. (2011) French national reference center for imported malaria study group. Severe imported plasmodium falciparum malaria, France, 1996-2003. Emerg Infect Dis 17: 807-813.

17. Trampuz A, Jereb M, Muzlovic I, Prabhu RM (2003) Clinical review: Severe malaria. Crit Care 7: 315-323.

18. Kain KC, Harrington MA, Tennyson S, Keystone JS (1998) Imported malaria: Prospective analysis of problems in diagnosis and management. Clin Infect Dis 27: 142-149.

19. Mali S, Kachur SP, Arguin PM (2012) Division of Parasitic Diseases and Malaria, Center for Global Health; Centers for Disease Control and Prevention (CDC), Malaria surveillance- United States, 2010. MMWR Surveill Summ 61: 1-17.

20. Phillips A, Bassett P, Zeki S, Newman S, Pasvol G (2009) Risk factors for severe disease in adults with falciparum malaria. Clin Infect Dis 48: 871-878.

21. Schwake L, Streit JP, Edler L, Encke J, Stremmel W, et al. (2008) Early treatment of imported falciparum malaria in the intermediate and intensive care unit setting: an 8-year single-center retrospective study. Crit Care 12: 16-22.

22. Mueller I, Galinski MR, Baird JK, Carlton JM, Kochar DK, et al. (2009) Key gaps in the knowledge of Plasmodium vivax, a neglected human malaria parasite. Lancet Infect Dis 9: 555-566.

23. Baird JK (2007) Neglect of Plasmodium vivax malaria. Trends Parasitol 23: 533-539.

24. Sharma A, Khanduri U (2009) How benign is benign tertian malaria? J Vector Borne Dis 46: 141-144.

25. Singh H, Parakh A, Basu S, Rath B (2011) Plasmodium vivax malaria: is it actually benign? J Infect Public Health 4: 91-95.

26. González A, Nicolás JM, Muñoz J, Castro P, Mas J, et al. (2009) Severe imported malaria in adults: retrospective study of 20 cases. Am J Trop Med Hyg 81: 595-599.

27. Dondorp AM, Lee SJ, Faiz MA, Mishra S, Price R, et al. (2008) The relationship between age and the manifestations of and mortality associated with severe malaria. Clin Infect Dis 47: 151-157.

28. Newman RD, Parise ME, Barber AM, Steketee RW (2004) Malaria-related deaths among U.S. travelers, 1963-2001. Ann Intern Med 141: 547-555.
29. Rabe C, Paar WD, Knopp A, Münch J, Musch A, et al. (2005) Malaria in the emergency room. Results of the emergency treatment of 137 patients with symptomatic malaria. Dtsch Med Wochenschr 130: 145-149.

30. Mühlberger N, Jelinek T, Behrens RH, Gjørup I, Coulaud JP, et al. (2003) Surveillance importierter Infektionen in Deutschland Surveillance Networks. Age as a risk factor for severe manifestations and fatal outcome of falciparum malaria in European patients: Observations from TropNetEurop and SIMPID Surveillance Data. Clin Infect Dis 36: 990-995.

31. Schwartz E, Sadetzki S, Murad H, Raveh D (2001) Age as a risk factor for severe Plasmodium falciparum malaria in nonimmune patients. Clin Infect Dis 33: 1774-1777.

32. Gjørup IE, Rønn A (2002) Malaria in elderly nonimmune travelers. J Travel Med 9: 91-93.

33. Koh KH, Chew PH, Kiyu A (2004) A retrospective study of malaria infections in an intensive care unit of a general hospital in Malaysia, Singapore. Med J 45: 28-36.

34. Legros F, Bouchaud O, Ancelle T, Arnaud A, Cojean S, et al. (2007) The French National Reference Centers for Imported and Autochthonous Malaria Epidemiology and Chemosensitivity Network. Risk factors for imported fatal Plasmodium falciparum malaria, France, 1996-2003. Emerg Infect Dis 13: 883-888.

35. Krause G, Schöneberg I, Altmann D, Stark K (2006) Chemoprophylaxis and malaria death rates. Emerg Infect Dis 12: 447-451.

36. Bruneel F, Hocqueloux L, Alberti C, Wolff M, Chevret S, et al. (2003) The clinical spectrum of severe imported falciparum malaria in the intensive care unit: Report of 188 cases in adults. Am J Respir Crit Care Med 167: 684-689.

37. Oliveira FJ, Lacerda MV, Brasil P, Ladislau JL, Tauil PL, et al. (2010) Malaria in Brazil: An overview. Malar J 9: 115.

38. Matteelli A, Colombini P, Gulletta M. Castelli F, Carosi G, et al. (1999) Epidemiological features and case management practices of imported malaria in northern Italy 1991-1995. Trop Med Int Health 4: 653-657.

39. Lyke KE, Burges R, Cissoko Y, Sangare L, Dao M, et al. (2004) Serum levels of the proinflammatory cytokines interleukin-1 beta (IL-1beta), IL-6, IL-8, IL-10, tumor necrosis factor alpha, and IL-12(p70) in Malian children with severe Plasmodium falciparum malaria and matched uncomplicated malaria or healthy controls. Infect Immun 72: 5630-5637.

40. Jennings RM, Souza JB, Todd JE, Armstrong M, Flanagan KL, et al. (2006) Imported Plasmodium falciparum malaria: are patients originating from disease-endemic areas less likely to develop severe disease? A prospective, observational study. Am J Trop Med Hyg 75: 1195-1199.

41. Akanmori BD, Kurtzhals JA, Goka BQ, Adabayeri V, Ofori MF, et al. (2000) Distinct patterns of cytokine regulation in discrete clinical forms of Plasmodium falciparum malaria. Eur Cytokine Netw 11: 113-118.

42. Idro R, Jenkins NE, Newton CR (2005) Pathogenesis, clinical features, and neurological outcome of cerebral malaria. Lancet Neurol 4: 827-840. 